\title{
Primary productivity of a Hevea forest in the Ivory Coast
}

\author{
B.A. Monteny \\ ORSTOM, Bioclimatologie-INRA, 78850 Thiverval-Grignon, France
}

\section{Introduction}

The objective of the study was to understand the impact of climatic parameters and soil-water factors on Hevea brasiliensis productivity (rubber). The primary production rates of a Hevea forest located in the humid tropical zone of the Ivory Coast have been calculated from a mathematical model based on determined experimental equations. Carbon dioxide flux density above the forest is measured by the energy balance method coupled with the Bowen ratio. This ratio, $\beta$, and the ratio of photochemical heat flux density for $\mathrm{CO}_{2}$ fixation to latent heat flux density, $f$, are determined from vertical profiles of points. The light- $\mathrm{CO}_{2}$ assimilation response curve of the Hevea forest, in relation to rain distribution and solar radiation availability, is used to calculate the daily estimates of organic carbon accumulation and, hence, the yearly dry matter production.

\section{Materials and Methods}

The equations describing individual inflow and output fluxes of forest stand productivity require: 1) the photosynthetic response of a plant stand and its evolution under the most important factors which control photosynthesis (radiation and water); 2) the daily and seasonal distributions of these factors; 3 ) the stand biomass $b$ (aerial and root) and the evolution of leaf area.

Net primary productivity, $N P$, results from the difference between the leaf carbon assimiliation rate $A$ and biomass respiration $R b$ (Jones, 1983):

$$
\begin{aligned}
N P & =\Sigma\left(A-R b_{0}\right)=\Sigma\left(A-R b_{d}-R b_{n}\right) \\
& =\Sigma\left(N A-R b_{n}\right)
\end{aligned}
$$

where $R b_{d}=$ biomass respiration daytime rate; $A b_{n}=$ biomass respiration nighttime rate; $\boldsymbol{A}=$ gross photosynthesis rate; $N A=$ net assimilation rate (daytime hours). Biomass respiration during the daytime (12 $h$ ) is assumed to be equal to that at night $\left(R b_{d}=R b_{n}\right)$.

The respiration rate $R$, extrapolated from the light response curve at zero solar radiation, corresponds to:

$R=R b_{n}+\mathrm{CO}_{2}$ soil $=R b_{\text {aerial }}+R_{\text {root }}+R_{\text {soil }}$

Soil carbon flux, $\mathrm{CO}_{2}$ soil, originates from the decomposition of litter and subsurface root hairs + root respiration: $\mathrm{CO}_{2}$ soil $=\Sigma\left(R_{\text {soil }}+\right.$ $R_{\text {root }}$ ). Soil $\mathrm{CO}_{2}$ measurements (involving an enclosure and ain air flow system, Perrier et al., 1976) show that the fluxes do not change during a $24 \mathrm{~h}$ period but that they vary more particularly with changes in subsurface soil water content.

Measurements were carried out in a SAPH Hevea plantation, at Dabou-Ousrou, near Abidjan $\left(5^{\circ} 19^{\prime} \mathrm{N}, 04^{\circ} 30^{\prime} \mathrm{W}\right)$, Ivory Coast. The tropical forest zone is under the influence of the 
intertropical convergence motion (ITC) which determines the climate. The climate of the forest zone has 2 dry seasons: DecemberMarch and August-September and 2 wet seasons with the most important from April to July. The plantation is a 7000 ha more or less flat land, situated in the southern part of the Ivorian tropical forest zone, $50 \mathrm{~km}$ from the Guinea Gulf coast.

From air and soil $\mathrm{CO}_{2}$ flux measurements using micrometeorological methods (Allen et al., 1974; Saugier and Ripley, 1974), experimental equations have been determined which express the net assimilation rate as a function of stand characteristics in relation to environmental factors (for more details, see Monteny, 1987).

\section{Results and Discussion}

The light-photosynthesis curves for the Hevea forest canopy present a maximum net photosynthesis at $1.85 \mathrm{mg}$ $\mathrm{CO}_{2} \cdot \mathrm{m}^{-2} \cdot \mathrm{s}^{-1}$ for a young canopy (2-3 mo, curve 1) and decreases to $0.5 \mathrm{mg} \mathrm{CO}{ }_{2}$. $\mathrm{m}^{-2} \cdot \mathrm{s}^{-1}$ for an older one (Dec.-Jan.), both without soil-water deficit (Fig. 1), fitted results from different days of measurement during 2 mo.

The light response curves show a tendency towards light saturation. The carbon assimiliation is sensitive to soil-water status, as seen for the photosynthesis curve 2 due to the increase of the stomatal resistances. The observed decrease in net $\mathrm{CO}_{2}$ assimiliation (Dec.-Jan.) is partly due to the deposition of cuticular wax (leaf ageing) and to the effect of a water stress period during the short dry season in August.

The global outgoing $\mathrm{CO}_{2}$ flux at night is equal to $0.44 \mathrm{mg} \mathrm{CO} 2 \cdot \mathrm{m}^{-2} \cdot \mathrm{s}^{-1}$. Root respiration is assumed to be proportional to root dry weight, as it is for shoot respiration. From the soil $\mathrm{CO}_{2}$ flux and the biomass measurements, the calculated respiration of aboveground biomass $R b_{n}$ is $0.15 \mathrm{mg} \mathrm{CO}{ }_{2} \cdot \mathrm{m}^{-2} \cdot \mathrm{s}^{-1}$. During the wet season, the ratio of $\mathrm{CO}_{2}$ soil flux to the $\mathrm{CO}_{2}$ canopy fixation is nearly unity, indicating that, in humid tropics, carbon turnover is very fast until the ground floor humidity limits litter decomposition or when the leaf photosynthesis decreases.

The daily net productivity, NP, of the Hevea forest is the difference between the net $\mathrm{CO}_{2}$ absorption calculated at $15 \mathrm{~min}$ intervals from 6:00-18:00 $h$ (based on solar radiation data available on 16 days and the light response curves in Fig. 1) and the night biomass respiration from

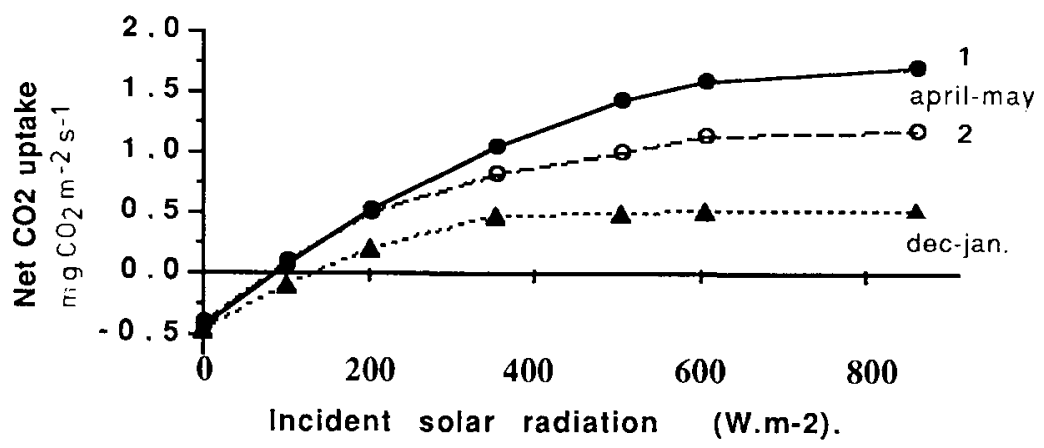

Fig. 1. Photosynthetic light response curves for the whole Hevea forest: young canopy without water limitation: Aprit-May (1); young canopy with water limitation: O: April-May (2); older canopy without water limitation: $\mathbf{A}$ : Dec. - Jan. 


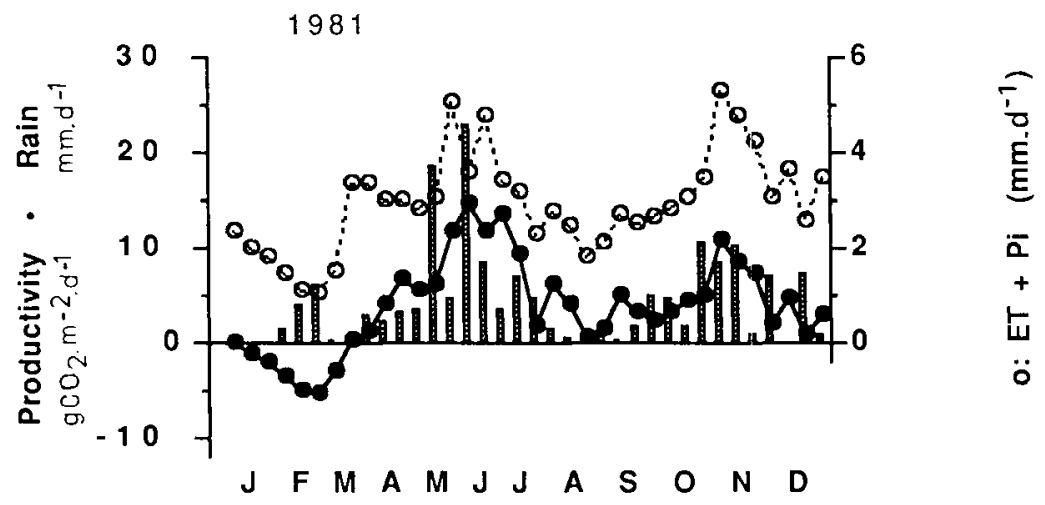

Fig. 2. Seasonal changes of the simulated dry matter production (-) of a $19 \mathrm{yr}$ old Hevea stand in relation to rainfall (目) and total evaporation rate $E T+P_{i}(O)$.

18:00-6:00 h. The depletion of soil water in the root zone affects the photosynthetic leaf capacities (Fig. 1) and the watervapor exchanges (Fig. 2). We consider the ratio of actual evapotranspiration to equilibrium evaporation, ETR/Eto, as a modulation factor representing the effect of water stress on net stand productivity (Monteny, 1987). The coefficient of conversion from carbon dioxide to dry matter is $0.56 \mathrm{~g} \mathrm{DM}^{\mathrm{g} \mathrm{CO}} \mathrm{CO}^{-1}$.

The annual evolution of the calculated primary production rate of a $19 \mathrm{yr}$ old rubber forest is presented in Fig. 2. It shows important variations during the year: 1) May-June: high dry matter production rates after leaf regrowth without soil water limitation; 2) July-August-September: decreased dry matter production rates, in relation to the attenuation of solar radiation by clouds from the ITC and the depletion of soil water at the end of the short dry season; 3) October-November: the physiological ageing of leaves associated with stomata becoming increasingly plugged with cuticular wax reduced the daily net canopy assimilation rates for $\mathrm{CO}_{2}$; 4) January-February: soil water availability was the main factor respons- ible for reduced leaf photosynthetic activity and physiological modification before leaf fall. At the end of the leaf span, global respiration rate of the stand was higher than the assimilation rate of the canopy, which explains the negative rates of dry matter production.

The estimated annual net productivity of the Hevea forest is $13.8 \mathrm{~T} \mathrm{DM} \cdot \mathrm{ha}^{-1} \cdot \mathrm{yr}^{-1}$ compared with the current annual increment: $8.1 \mathrm{~T} \mathrm{DM} \cdot \mathrm{ha}^{-1} \cdot \mathrm{yr}^{-1}$ measured between 11 and $19 \mathrm{yr}$. Taking into account leaf and shoot litter fall and latex sampling $\left(2.4+3.8+1.6 \mathrm{~T} \mathrm{DM} \cdot \mathrm{ha}^{-1} \cdot \mathrm{yr}^{-1}\right.$, respectively), the total annual increment would be $15.9 \mathrm{~T} \mathrm{DM} \cdot \mathrm{ha}^{-1} \cdot \mathrm{yr}^{-1}$ or $15 \%$ higher than the estimated net productivity. The efficiency of solar radiation conversion into net annual production is $1.7 \%$.

\section{Conclusion}

In the humid tropical regions of West Africa, two climatic factors affect the forest dry matter production: rain distribution and radiation quantities. These factors, depending upon the shift of the ITC, are 
responsible for the low atmospheric $\mathrm{CO}_{2}$ assimilation rate by forests. The wet seasons are commonly cloud-covered and it is the litter decomposition which supplies most of the $\mathrm{CO}_{2}$ to the canopy. Leaf lifespan activities are influenced by morphological modifications with ageing, reducing, on the other hand, Hevea photosynthetic efficiency.

\section{References}

Allen L.H., Hanks R.J. \& Gardner H.R. (1974) Carbon dioxide uptake by wide row grain sor- ghum computed by the profile Bowen ratio. Agron. J. 66, 35-41

Jones H.G. (1983) in: Plants and Microclimate. Cambridge University Press, Cambridge, pp. 323

Monteny B.A. (1987) Contribution à l'étude des interactions végétation-atmosphère en milieu tropical humide. Importance du rôle du système forestier dans le recyclage des eaux de pluie. Ph.D. Thesis, Université de Paris XI, Orsay

Perrier A., Itier B. \& Jaussely B. (1976) Etude de la photosynthèse en plein champ. In: Les processus de la production végétale primaire. (Moyse A., ed.), Gauthier-Villars, Paris, pp. 113136

Saugier B. \& Ripley E.A. (1974) A sensitive device for recording atmospheric $\mathrm{CO}_{2}$ profiles. J. Appl. Ecol. 11, 103-110 